\title{
Dynamic Phasor-Based Modeling of Unbalanced Radial Distribution Systems
}

\author{
Zhixin Miao, Senior Member, IEEE, Lakshan Piyasinghe, Student Member, IEEE, Javad Khazaei, Student \\ Member, IEEE, Lingling Fan, Senior Member, IEEE
}

\begin{abstract}
This paper develops an analytical model of an unbalanced radial distribution system consisting of a single-phase PV, a three-phase induction machine load, a three-phase power factor correction capacitor (PFC) and a load. The analytical model is based on dynamic phasors (DP) for $a b c$ phases. The single-phase PV model includes inverter current control (Proportional Resonance (PR) controller), an L or an LCL filter. The induction machine model is based on positive-, negative-, and zero-sequence components' dynamic phasors. The sequencebased induction machine model was converted to the DP-abc reference frame and interconnected with other grid components.

The developed analytical model is capable of small-signal analysis and can be used to identify variety of stability and/or harmonic issues in distribution networks, e.g., instability due to weak grid. Impact of unbalance on system dynamic performance can also be investigated using this model. The analytical model is benchmarked with a high-fidelity model built in Matlab/SimPowerSystems where power electronic switching details are included. The small-signal analysis results are validated via Matlab/SimPowerSystems time-domain simulations.
\end{abstract}

Index Terms-Dynamic Phasor (DP), Single-Phase Photovoltaic, Induction Machine, Small-Signal Analysis

\section{INTRODUCTION}

Increasing efficiency and decreasing cost of solar technology promotes substantial growth of Photovoltaic (PV) power integration in modern power systems. The total capacity of grid connected PV systems has increased from $300 \mathrm{MW}$ in 2000 to $21 \mathrm{GW}$ in 2010 [1]. PV has shared a fair amount of renewable energy penetration in microgrids where the PV power supplies electrical loads for local communities [2]-[4]. New government policies and incentives encourage more and more single-phase PV systems to be connected. In addition, induction machine based loads are dominant in distribution systems. Analytical models of such unbalanced distribution systems would provide insights of the system and further be used for small-signal and large-signal stability analysis. The analysis will help identify stability issues and mitigate related problems.

For unbalanced systems, abc frame-based dynamic models can be used for dynamic performance examination. Simulation packages such as PSCAD [5] and Matlab/SimPowerSystems [6] are based on simulation models with instantaneous variables, e.g., instantaneous voltages and currents in three phases. Conventional linearization at an operating condition cannot be applied to these models due to the periodic varying state

Z. Miao, L. Piyasinghe, J. Khazaei, and L. Fan are with Department of Electrical Engineering at University of South Florida, Tampa, FL 33620 (Email: zmiao@usf.edu). variables. The necessary condition for small-signal analysis is to have constant values for state variables at steady state [7]. Transforming the models to a synchronous rotating reference $(d q)$ frame is the most common technique utilized to overcome the above problem [7]. However the negative-sequence components presented in an unbalance system will be converted to $120 \mathrm{~Hz}$ ac variables in a $d q$-reference frame. Hence, $d q$ reference frame-based models do not offer the capability of small-signal analysis under unbalanced topology and operating conditions.

On the other hand, dynamic phasor (DP)-based modeling, an averaging technique, has been demonstrated to be capable of converting periodic varying state variables into dc state variables [8]-[16]. It has been used in electrical machines analysis [8], [9], dc/dc converter analysis [15], distribution system analysis [13], and HVDC and FACTS system modeling and analysis [11], [12], [14]. For example, [14] presents an averaged model of LCC based HVDC system which is capable of representing low frequency dynamics of the converters at both AC and DC sides. DP models make small-signal analysis feasible. Small-signal analysis based on DP models have been carried out in [13], [16]. DP modeling technique also provides very accurate simulations for larger time steps [9], [14], [15].

Moreover, DP-based modeling can take into consideration of unbalance. For example, in [9], an induction machine (IM) model as well as a permanent magnet synchronous generator (PMSG) model in unbalanced conditions have been developed based on positive, negative, and zero (PNZ) variables. In [11], the dynamic phasor-based modeling technique is used to model the Unified Power Flow Controller (UPFC). The model is expressed in PNZ variables and can be used to study the effect of unbalanced operation. [16] presents a DP-based model taking into consideration of positive-, negative, and zero-sequence elements of a synchronous generator and its voltage controls. Tests on a single-machine infinite-bus system is conducted.

The above mentioned references [9], [11], [13] consider only unbalanced operation instead of unbalanced topology.The objective of this paper is to model, analyze and simulate an unbalanced distribution system with both complex loads such as IM and renewables such as inverter interfaced PVs. To the authors' best knowledge, the literature lacks a comprehensive modeling approach for unbalanced distribution systems that is suitable for both small-signal analysis and nonlinear timedomain simulation.

An effort has been taken in [17] to model a distribution system with unbalanced topology. The system model is ex- 
pressed by DPs of fundamental frequency in in $a b c$ frame and the system contains a synchronous generator and a singlephase inverter. Our proposed work will improve the modeling strategy in two aspects and therefore tackle comprehensive dynamic phenomena of unbalanced distribution systems.

- A more comprehensive inverter control will be modeled in this paper. The inverter is modeled in [17] as a PQ controlled voltage source. Current controls are ignored. Interactions between the current controls of inverters and the grid can lead to resonances [18]. Therefore, ignoring current controls of a grid-connected inverter will lead to the omission of certain dynamics. The current controls of a PV inverter will be modeled in our paper.

- A more comprehensive system model will be pursued in this paper. The network model is treated as algebraic equations in [16], [17] with dynamics of inductors and capacitors ignored. Each source in the system is treated as a voltage source. The sources are interfaced through voltage/current algebraic relationship derived based on the network model. In our paper, a different modeling strategy is adopted. Each source is modeled as a current source. The sources are then interfaced through network dynamics. Using this strategy, the network dynamics due to inductors and capacitors will not be omitted.

In summary, this paper investigates comprehensive modeling of unbalanced distribution systems using dynamic phasors. The system consists of a three-phase induction machine load, three-phase resistive loads, a PFC and a single-phase PV system. The three-phase induction machine, will be modeled based on pnz dynamic phasors and then be converted to $a b c$ phasors. A single-phase PV system at phase $a$ will be modeled in phase $a$ phasors. The entire system model will be obtained through a current source based integration technique. The major contributions of this paper include a comprehensive dynamic modeling approach for unbalanced radial distribution systems. Applications of the model will be demonstrated in small-signal analysis and fast and accurate simulation.

Though the study system has only one single-phase source, the proposed modeling method can be applied to radial systems with multiple unbalanced components. The easiness of integrating multiple unbalanced elements will be shown in Section III. The model is based on first harmonic DPs and therefore is suitable to study unbalance in the ac network and the resulting $120 \mathrm{~Hz}$ harmonics in the torque and speed in a three-phase induction machine.

The rest of the paper is organized as follows. In Section II, the dynamic phasor concept will be described and the principle of unbalanced poly-phase DP modeling will be summarized. The distribution system configuration is presented in Section III. Dynamic Phasor modeling of components, including a PV, an induction machine, and the grid with a PFC, is investigated in Sections III as well. Section IV presents case studies to demonstrate the capability of the developed analytical model in small-signal analysis and time-domain simulations. Section $\mathrm{V}$ concludes the paper.

\section{DyNAMIC PHASOR CONCEPT}

Dynamic Phasor (DP) models provides abundant merits, including: (i) the capability of small-signal analysis and (ii) availability of large step size simulations. The main idea of DP comes from describing the waveform $x(\tau)$ on interval $[t-T, t]$ by Fourier Series [8]:

$$
x(\tau)=\sum_{k=-\infty}^{\infty} X_{k}(t) e^{j k \omega_{s} t}
$$

where $\omega_{s}=2 \pi / T$ and $X_{k}$ is the $k$-th complex Fourier coefficient or Dynamic Phasor (DP). Due to the fact that these coefficients are constant at steady state, the DP model can be linearized for small-signal analysis. The $k$-th DP of the time varying signal $x(\tau)$ can be obtained by (2) [8]:

$$
X_{k}(t)=\frac{1}{T} \int_{t-T}^{t} x(\tau) e^{-j k \omega_{s} \tau} d \tau=\langle x\rangle_{k}(t) .
$$

where $\langle.\rangle_{k}$ denotes the $k t h$ harmonic DP.

The main characteristics of the DP modeling are described as follows [8].

$$
\left\{\begin{array}{l}
\left\langle\frac{d x}{d t}\right\rangle_{k}=\frac{d X_{k}}{d t}+j k \omega X_{k} \\
\langle x . y\rangle_{k}=\sum_{l=-\infty}^{\infty}\left(X_{k-l} . Y_{l}\right)
\end{array}\right.
$$

Equation (3) describes the relationship between the DP of a derivative versus the DP of the original signal while (3) describes the relationship between the DP of a product versus the DPs of the individual variables.

In this study, the main aim is to derive the DP model of a distribution system composed of a single-phase PV, a three-phase induction machine, a PFC and distribution lines represented by RL circuits. The DP models in the abc frame can be derived by converting the DP model from the positive-, negative-, and zero-sequence (pnz) reference frame [9]. The original signals in the abc frame can be expressed by pnz DPs as follows.

$$
\left[\begin{array}{l}
x_{a} \\
x_{b} \\
x_{c}
\end{array}\right](\tau)=\sum_{l=-\infty}^{\infty} e^{j k \omega_{s} \tau} \underbrace{\frac{1}{\sqrt{3}}\left(\begin{array}{ccc}
1 & 1 & 1 \\
\alpha^{*} & \alpha & 1 \\
\alpha & \alpha^{*} & 1
\end{array}\right)}_{M}\left[\begin{array}{c}
X_{p, l} \\
X_{n, l} \\
X_{z, l}
\end{array}\right]
$$

where $l$ stands for the harmonic component index, $M$ is the transformation matrix $\left(M^{H}=M^{-1}\right)$ from $p n z$ to $a b c$ and $p$, $n$, and $z$ stand for positive-, negative-, and zero-sequences. It is easy to see that the DPs of abc variables have the following relationship with the DPs of $p n z$-sequences.

$$
\left[\begin{array}{c}
X_{a, l} \\
X_{b, l} \\
X_{c, l}
\end{array}\right]=M\left[\begin{array}{c}
X_{p, l} \\
X_{n, l} \\
X_{z, l}
\end{array}\right]
$$

In the next section, after introducing the entire system topology, the DP models of each element will be presented one by one, which will be integrated into the overall system model. 


\section{System Configuration AND Modeling}

The parameters presented in [17], [19] are utilized for the proposed study system shown in Fig. 1. The distributed system consists of a single-phase PV station installed in phase $a$ of the system, a 3-phase induction machine, a 3-phase PFC and a 3-phase load.

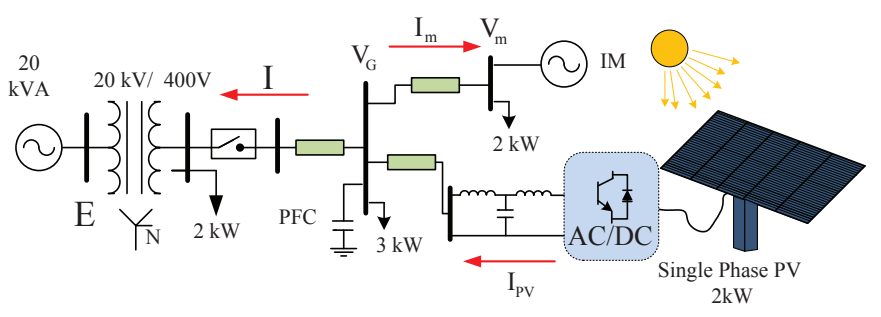

Fig. 1. The study system.

\section{A. DP Model of a Single-Phase PV}

Traditionally, two-stage converters (a DC-AC converter after a DC-DC converter) have been used for PV systems. Twostage converters need additional devices compared with singlestage converters. Therefore, single-stage converters have been implemented in PV grid integration [20]-[23]. The basic configuration of a single-phase PV is illustrated in Fig. 2. The main elements of the single-stage PV are the Proportional Resonant (PR) current controller and the output filters.

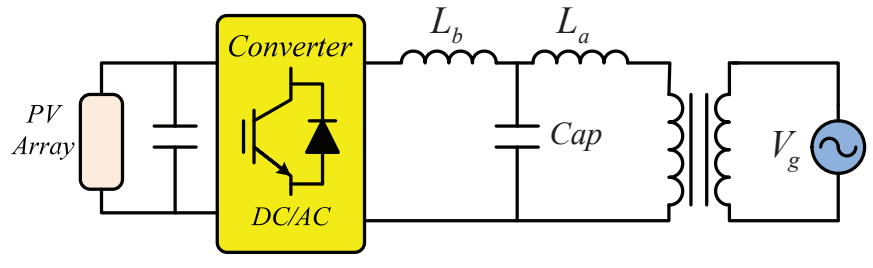

Fig. 2. Basic configuration of PV system.

Fig. 2 shows the basic configuration of a LCL filter in a single-phase PV. It is composed of two inductances and one capacitor connected to the grid through a single-phase transformer. The simplified model of PV connected to the grid with an L or an LCL filter has been illustrated in Fig. 3. The output voltage of the DC-AC converter is $v_{c o n}$, the filter inductances are $L_{a}$ and $L_{b}$, and the grid side voltage is $v_{G}$. Note that the transformer can be represented by an inductor $L_{T}$. Therefore, $L_{2}=L_{b}$ and $L_{1}=L_{a}+L_{T}$. Furthermore, for a PV connected to an $\mathrm{L}$ filter, if $L_{f}$ is used for the $\mathrm{L}$ filter inductance, $L_{3}=L_{f}+L_{T}$.

The time-domain equations of the system for the LCL filter are listed as follows.

$$
\begin{cases}L_{1} \frac{d i_{1}}{d t} & =v_{c 1}-v_{G} \\ L_{2} \frac{d i_{2}}{d t} & =v_{c o n}-v_{c 1} \\ C_{1} \frac{d v_{c 1}}{d t} & =i_{2}-i_{1}\end{cases}
$$

The dynamics of the PV system with LCL filter in DP is expressed as follows. It should be noted that only the first

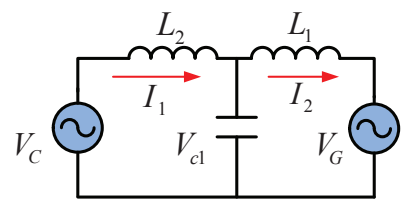

(a)

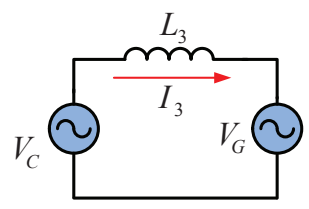

(b)
Fig. 3. Simplified PV model with different filters. (a): LCL filter, (b): L filter

harmonic is considered for the derivation of dynamic phasor coefficients.

$$
\left\{\begin{array}{l}
\dot{I}_{1}=\frac{1}{L_{1}}\left(V_{c 1}-V_{G}\right)-j \omega_{s} I_{1} \\
\dot{I}_{2}=\frac{1}{L_{2}}\left(V_{c o n}-V_{c 1}\right)-j \omega_{s} I_{2} \\
\dot{V}_{c 1}=\frac{1}{C_{1}}\left(I_{2}-I_{1}\right)-j \omega_{s} V_{c 1}
\end{array}\right.
$$

It should be noted that $V_{c o n}$ is the DP of the output voltage of PV inverter. For an L filter enabled PV system, the basic DP equation of the PV system connected to grid is:

$$
\dot{I}_{3}=\frac{1}{L_{3}}\left(V_{c o n}-V_{G}\right)-j \omega_{s} I_{3} .
$$

A detailed control block diagram of the single-stage single phase PV is illustrated in Fig 4. It is composed of a Maximum Power Point Tracking (MPPT) unit, a Proportional Resonant (PR) controller, a Phase-Locked-Loop (PLL), and a Pulse Width Modulation (PMW) pulse generation unit. In this paper, the effect of the MPPT dynamics and the PLL has been neglected for simplicity and special attention has been dedicated to the PR controller and the LCL filter.

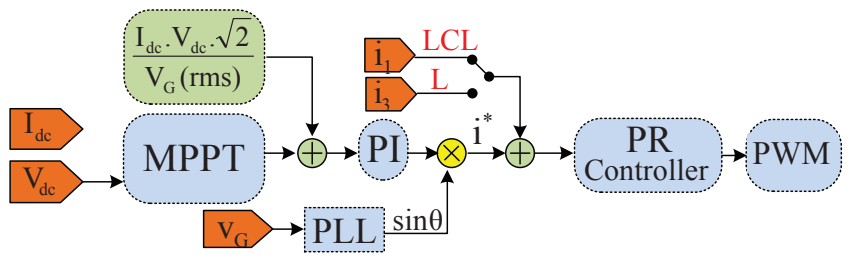

Fig. 4. Basic control of a single-phase PV.

1) DP model of a PR controller: PR control is used to track ac signals. The PR controller in Fig. 4 tries to provide unity power factor power from the PV. Therefore, the current reference is synchronized with the grid voltage through a PLL. The dynamics of a PR controller considering only the fundamental harmonics can be expressed as:

$$
\begin{aligned}
v_{\text {con }} & =\left(K_{p}+\frac{K_{r} s}{s^{2}+\left(\omega_{s}\right)^{2}}\right)\left(i^{*}-i_{1}\right) \\
& =\left[K_{p}+K_{r}\left(\frac{0.5}{s+j \omega_{s}}+\frac{0.5}{s-j \omega_{s}}\right)\right]\left(i^{*}-i_{1}\right)
\end{aligned}
$$

where $i^{*}$ is the reference current comes from PV array. In the analytical model, the dynamics of PLL and MPPT are neglected for simplicity of analysis. $i_{1}$ is the grid current when the PV enhanced with LCL filter. In a case where the PV is interconnected with an $\mathrm{L}$ filter, $i_{1}$ will be replaced by $i_{3}$, which is the grid current. The rest of the modeling part has considered 
the LCL filter only. Define intermediate state variables $x_{1}$ and $x_{2}$, where

$$
\begin{cases}\left(s+j \omega_{s}\right) x_{1} & =0.5\left(i^{*}-i_{1}\right) \\ \left(s-j \omega_{s}\right) x_{2} & =0.5\left(i^{*}-i_{1}\right) .\end{cases}
$$

Rewriting (10) in time domain gives (11).

$$
\left\{\begin{array}{l}
\frac{d x_{1}}{d t}+j \omega_{s} x_{1}=0.5\left(i^{*}-i_{1}\right) \\
\frac{d x_{2}}{d t}-j \omega_{s} x_{2}=0.5\left(i^{*}-i_{1}\right)
\end{array}\right.
$$

Applying the characteristics of DP, the DP relationship can be derived

$$
\left\{\begin{array}{l}
\frac{d X_{1}}{d t}=0.5\left(I^{*}-I_{1}\right)-2 j \omega_{s} X_{1} \\
\frac{d X_{2}}{d t}=0.5\left(I^{*}-I_{1}\right)
\end{array}\right.
$$

The DP of the converter output voltage's fundamental frequency component can be expressed as:

$$
V_{\text {con }}=K_{p 1}\left(I^{*}-I_{1}\right)+K_{r 1}\left(X_{1}+X_{2}\right)
$$

The DP model of a single-phase PV consists of (7), (12) and (13). The current reference $I^{*}$ comes from this equation: $I^{*}=\frac{\sqrt{2} V_{d c} I_{d c}}{V_{G}(r m s)}=\frac{\sqrt{2} P_{r e f}}{V_{G}(r m s)}$.

\section{B. DP model of an induction machine}

Since the single-phase PV will introduce unbalance in the distribution system, the induction machine will be modeled to include unbalance effect. Negative-sequence components in the stator voltage can cause a clockwise rotating stator flux. When this flux is interacting with the counter-clockwise rotating rotor flux, a $120 \mathrm{~Hz}$ torque ripple will appear. In turn, the rotating speed will have ripples with $120 \mathrm{~Hz}$ frequency. To count in the negative effect, the dynamic model of a three-phase induction machine in [9] based on pnz-sequence components is adopted in this paper. The space-vector model of a squirrel-cage induction machine with magnetic saturation and slot harmonics neglected is presented as follows.

$$
\left\{\begin{array}{l}
\vec{v}_{s}=\left(r_{s}+L_{s} \frac{d}{d t}\right) \vec{i}_{s}+L_{m} \frac{d}{d t} \vec{i}_{r} \\
0=L_{m} \frac{d}{d t} \vec{i}_{s}+\left(r_{r}+L_{r} \frac{d}{d t}\right) \vec{i}_{r}-j \omega_{r} \frac{P}{2}\left(L_{m} \vec{i}_{s}+L_{r} \vec{i}_{r}\right) \\
J \frac{d}{d t} \omega_{r}=\frac{3 P}{4} L_{m} \Im\left(\vec{i}_{s} \vec{i}_{s}^{*}\right)-B \omega_{r}-T_{L}
\end{array}\right.
$$

where $\overrightarrow{v_{s}}, \overrightarrow{i_{s}}, \overrightarrow{i_{r}}$ denote the stator voltage, stator current and rotor current respectively. $T_{L}$ is the mechanical torque and $\omega_{r}$ is the rotor speed. $s$ and $r$ denote the stator and rotor quantities, respectively. $\Im$ denotes the imaginary part. The DP model of an induction machine can be derived by considering the positive- and negative-sequence components in stator/rotor voltages and currents, as well as the $\mathrm{dc}$ and the $120 \mathrm{~Hz}$ components in the rotating speed [9].

$$
\begin{array}{r}
V_{p s}=\left(r_{s}+j \omega_{s} L_{s}+L_{s} \frac{d}{d t}\right) I_{p s}+\left(j \omega_{s} L_{m}+L_{m} \frac{d}{d t}\right) I_{p r} \\
0=\left(j \omega_{s} L_{m}+L_{m} \frac{d}{d t}\right) I_{p s}+\left(r_{r}+j \omega_{s} L_{r}+L_{r} \frac{d}{d t}\right) I_{p r} \\
-j \omega_{r 0} \frac{P}{2}\left(L_{m} I_{p s}+L_{r} I_{p r}\right)-j \omega_{r 2} \frac{P}{2}\left(L_{m} I_{n s}^{*}+L_{r} I_{n r}^{*}\right) \\
V_{n s}^{*}=\left(r_{s}-j \omega_{s} L_{s}+L_{s} \frac{d}{d t}\right) I_{n s}^{*}-\left(j \omega_{s} L_{m}-L_{m} \frac{d}{d t}\right) I_{n r}^{*} \\
0=\left(L_{m} \frac{d}{d t}-j \omega_{s} L_{m}\right) I_{n s}^{*}+\left(r_{r}-j \omega_{s} L_{r}+L_{r} \frac{d}{d t}\right) I_{n r}^{*} \\
-j \omega_{r 0} \frac{P}{2}\left(L_{m} I_{n s}^{*}+L_{r} I_{n r}^{*}\right)-j \omega_{r 2}^{*} \frac{P}{2}\left(L_{m} I_{p s}+L_{r} I_{p r}\right) \\
J \frac{d}{d t} \omega_{r 0}=\frac{2 P}{4} L_{m} \Im\left(I_{p s} I_{p r}^{*}+I_{n s}^{*} I_{n r}\right)-B \omega_{r 0}-T_{L} \\
J \frac{d}{d t} \omega_{r 2}=\frac{2 P}{j 8} L_{m} \Im\left(I_{p s} I_{n r}-I_{n s} I_{p r}\right) \\
-\left(B+j 2 J \omega_{s}\right) \omega_{r 2}
\end{array}
$$

where subscripts $p$ and $n$ stand for positive and negative sequence components, respectively.

Since the DP model for the PV system is based on phase $a$, to integrate the induction machine model with the PV system model, the above $p n z$ model will be converted from and to the $a b c$ frame using the relationship presented in (5). The block diagram of the conversion has been illustrated in Fig. 5 .

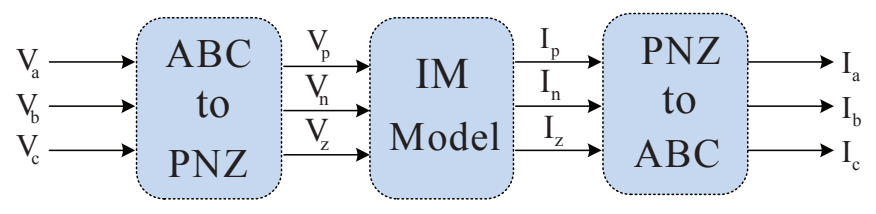

Fig. 5. Conversion from $a b c$ to $p n z$ and back to $a b c$ for an induction machine.

\section{PFC and the integrated system}

Considering that there is a three-phase PFC in parallel with the PV, the circuit model of the distribution system can be illustrated as in Fig. 6, where $C$ denotes the capacitance of the PFC, $I_{M}$ is the induction machine's stator current, $I$ is the line current, $R$ and $L$ are the distribution line's parameters, $R_{L}$ is the load model, and $E$ is the system voltage.

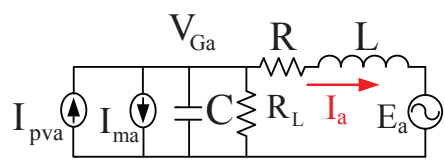

(a)

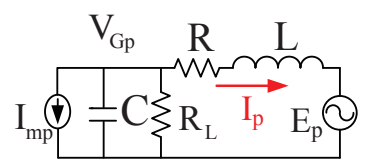

(b)
Fig. 6. (a): Circuit model of the distribution system with PV in phase $a$, (b): Circuit model of the distribution system in phase $b$ and $c$ 
For phase $a$, the DP model of the integrated system can be expressed as

$$
\left\{\begin{array}{l}
\frac{d}{d t} I_{a}=\frac{1}{L}\left(-\left(j \omega_{s} L+R\right) I_{a}+V_{G a}-E_{a}\right) \\
\frac{d}{d t} V_{G a}=\frac{1}{C}\left(-\left(j \omega_{s} C+\frac{1}{R_{L}}\right) V_{G a}-I_{m a}+I_{P V}-I_{a}\right)
\end{array}\right.
$$

where two state variables (grid voltage and grid current) have been introduced.

For phase $b$ and $c$, the DP model of the integrated system can be expressed as:

$$
\begin{cases}\frac{d}{d t} I_{p} & =\frac{1}{L}\left(-\left(j \omega_{s} L+R\right) I_{p}+V_{G p}-E_{p}\right) \\ \frac{d}{d t} V_{G p} & =\frac{1}{C}\left(-\left(j \omega_{s} C+\frac{1}{R_{L}}\right) V_{G p}-I_{m p}-I_{p}\right)\end{cases}
$$

where $p$ represents either phase $b$ or phase $c$.

In the proposed system integration approach, individual elements such as PV systems, induction machine loads and resistive loads are modeled as current sources or passive elements. Through the PFC dynamics and the grid inductor dynamics, the individual current sources are then integrated with the grid voltage. As long as the distribution system is radial, additional unbalanced elements can be modeled as shunt current sources or passive elements and easily integrated into the overall system model.

The entire system is composed of a PV system, an induction machine, a PFC and the RL line. As a total, 17 complex state variables are presented, including the line currents $\left(I_{a b c}\right)$, PFC voltage $\left(V_{G, a b c}\right)$, induction machine stator currents $\left(I_{s, p n}\right)$, induction machine rotor currents $\left(I_{r, p n}\right)$, induction machine rotor speed $\left(\omega_{r 0}, \omega_{r 2}\right)$, PV system state variables (output current $\left(I_{1}\right)$, current before filter $\left(I_{2}\right)$, voltage across the LCL filter capacitor $\left(V_{c 1}\right)$, the stator variables in the PR controller of the PV $\left(X_{1}\right.$ and $\left.X_{2}\right)$.

The complex state variables will be separated into real and imaginary components. Therefore, as a total, 34 real state variables are introduced for this DP model and small-signal analysis will show 34 eigenvalues.

\section{Case Studies}

The analytical model for the entire distribution system has been derived in Section III. The model was been built in Matlab/Simulink. The nonlinear analytical model can be linearized based on a certain operating point using Matlab function "linmod". Small-signal analysis can then be carried out for the linearized model. The same study system was also built in Matlab/SimPowerSystems based on the physical circuit connection. The Matlab/SimPowerSystems model captures power electronic switching details and therefore is considered high-fidelity simulation model.

Three case studies have been carried out.

- In the first case, the analytical model in Simulink is benchmarked with the high-fidelity model in SimPowerSystems. Dynamic simulation results are compared for the same dynamic event: a step change in load torque of the induction machine.

- In the second case, the effect of unbalance on the dynamic performance is investigated by applying a ramp change in irradiance of the PV. This dynamic event emulates the cloud effect on a PV and a distribution system.

- In the third case, the effect of the grid-line length on stability is investigated. Small-signal analysis analysis and time-domain simulation are carried out.

\section{A. Case Study 1}

In this part, the analytical model-based simulation results are compared with the Matlab/SimPowerSystems model-based simulation results (in short, Simpower). A single-phase PV is connected to the phase $a$ of the system at the Point of Common Coupling (PCC) shown as in Fig. 1. At $t=4 s$, the induction machine's mechanical torque was applied a step change from 28 N.M to 23 N.M.

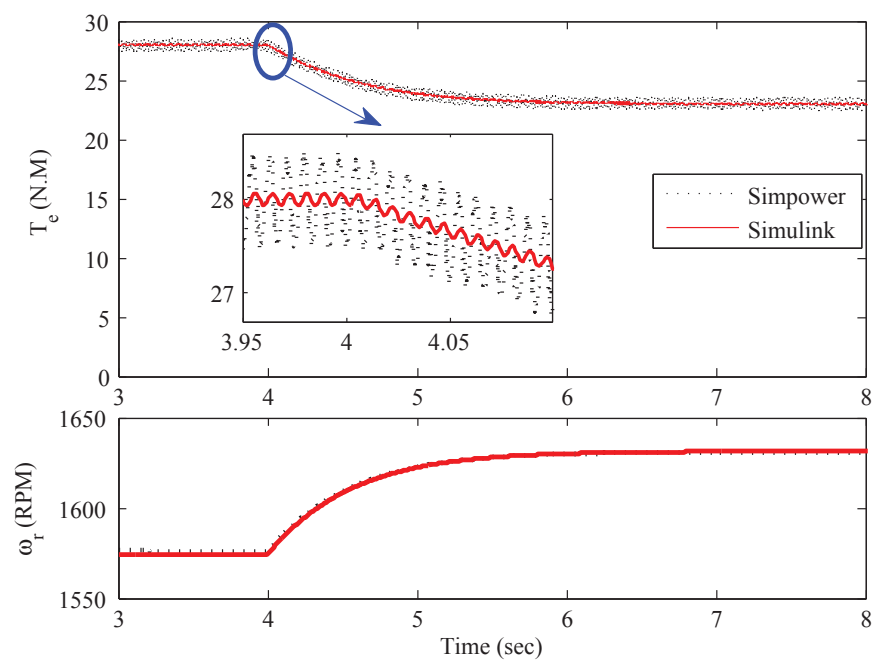

Fig. 7. Simulation results of torque and rotor speed due to a step change in mechanical torque (from 28 N.M to 23 N.M).

The simulation results of the electromagnetic torque and the rotor speed of the induction machine have been presented in Fig. 7. The dynamic responses from the two models match each other well.

The simulation results for the line current, the line voltage and the PV current are presented in Fig. 8. The results of the line current and the line voltage from both models match well, which demonstrates the accuracy of the analytical model derived in this paper. The PV current from SimPowerSystems simulation has dynamics related to MPPT control and the dcside capacitor. In the analytical model, MPPT effect and dcside dynamics are neglected. While the PV power is constant and $V_{G}$ has negligible variation, therefore the PV current of the analytical model is almost constant.

\section{B. Case Study 2}

Eigenvalue analysis for the system with and without PV has been conducted and the results are presented in Tables I and II. It can be observed from the tables that, due to the PV, five pairs of eigenvalues are introduced and these eigenvalues are related to PV state variables such the LCL capacitor voltage $V_{c 1}$, PR controller state variables $X_{1}, X_{2}$ and the PV current $I_{P V}$. 

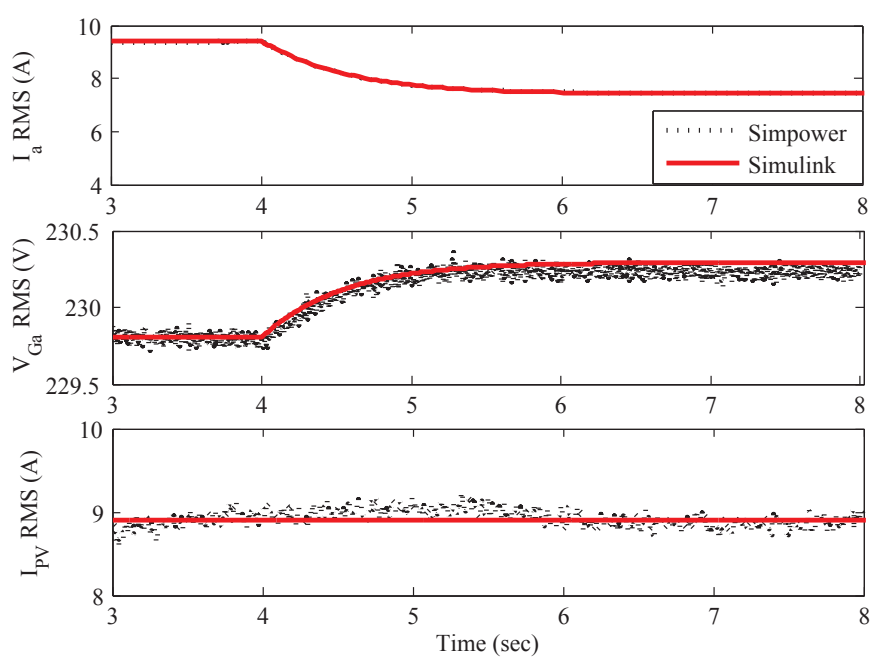

Fig. 8. Simulation results of the IM stator current, stator voltage and PV current due to a step change in mechanical torque (from 28 N.M to 23 N.M).

TABLE I

EIGENVALUES OF THE SYSTEM WITHOUT PV

\begin{tabular}{|c|c|c|c|}
\hline Eigenvalue & damping ratio $\%$ & frequency $(\mathrm{Hz})$ & dominant state \\
\hline$-959 \pm 5768 \mathrm{i}$ & 16.4 & $\overline{918)}$ & \multirow{6}{*}{$V_{G}, I$} \\
\hline$-966 \pm 5935 i$ & 16.07 & 945 & \\
\hline$-966 \pm 5935 i$ & 16.06 & 945 & \\
\hline$-959 \pm 5014 i$ & 18.78 & 798 & \\
\hline$-966 \pm 5181 i$ & 18.33 & 825 & \\
\hline$-966 \pm 5181 \mathrm{i}$ & 18.33 & 825 & \\
\hline$-133.37 \pm 308 \mathrm{i}$ & 39.68 & 49 & $I_{p s}$ \\
\hline$-137.95 \pm 117 \mathrm{i}$ & 76.37 & 18.6 & $I_{p r}$ \\
\hline$-133.38 \pm 445 \mathrm{i}$ & 28.69 & 70.9 & $I_{n s}$ \\
\hline$-137.95 \pm 637 \mathrm{i}$ & 21.15 & 101 & $I_{n r}$ \\
\hline$-0.76 \pm 754$ & 0.1 & 120 & $\omega_{r 2}$ \\
\hline$-1.54 \pm 0 \mathrm{i}$ & 100 & 0 & $\omega_{r}$ \\
\hline
\end{tabular}

TABLE II

EIGENVALUES OF THE SYSTEM WITH PV

\begin{tabular}{|c|c|c|c|}
\hline Eigenvalue & damping ratio $\%$ & frequency $(\mathrm{Hz})$ & dominant state \\
\hline$-966 \pm 5935 i$ & $16.06)$ & $944)$ & \\
\hline$-967 \pm 5848 i$ & 16.31 & 931 & \\
\hline$-993 \pm 5607 i$ & 17.43 & 892 & $V$ \\
\hline$-993 \pm 4853 i$ & 20.04 & 772 & $V_{G}, I$ \\
\hline$-966 \pm 5181 i$ & 18.33 & 824 & \\
\hline$-967 \pm 5094 \mathrm{i}$ & 18.65 & 810 & \\
\hline$-855 \pm 8475 \mathrm{i}$ & 10.04 & 1349 & \\
\hline$-855 \pm 7721 \mathrm{i}\}$ & 11.01 & 1229 & $V_{c 1}$ \\
\hline$-1.87 \pm 754 \mathrm{i}$ & 0.25 & 120 & \\
\hline$-1.87 \pm 0.10 \mathrm{i}\}$ & $99.8\}$ & $0.02\}$ & $X_{1}, X_{2}$ \\
\hline$-8218 \pm 377 \mathrm{i}$ & 99.9 & 60 & $I_{p v}$ \\
\hline$-133.37 \pm 308 \mathrm{i}$ & 39.68 & 49 & $I_{p s}$ \\
\hline$-137.96 \pm 117 i$ & 76.23 & 18.6 & $I_{p r}$ \\
\hline$-133.37 \pm 445 i$ & 28.68 & 70.9 & $I_{n s}$ \\
\hline$-137.96 \pm 637 i$ & 21.17 & 101 & $I_{n r}$ \\
\hline$-0.75 \pm 754$ & 0.1 & 120 & $\omega_{r 2}$ \\
\hline$-1.52 \pm 0 \mathrm{i}$ & 100 & 0 & $\omega_{r}$ \\
\hline
\end{tabular}

a) PV irradiance change: In this part, the effect of PV irradiance change will be simulated in both Matlab/Simulink and Matlab/SimPowersystems. The PV irradiance was set to $1000 \mathrm{~W} / \mathrm{M}^{2}$ previously. A ramp change will be applied at $t=4 s$ to decrease the irradiance to $200 \mathrm{~W} / \mathrm{M}^{2}$ in $0.2 \mathrm{sec}$. Then after $1.4 \mathrm{sec}$, the irradiance will be set back to 1000 $W / M^{2}$. The change of irradiance has been illustrated in detail in the first figure of Fig. 9. The second figure of Fig. 9 shows
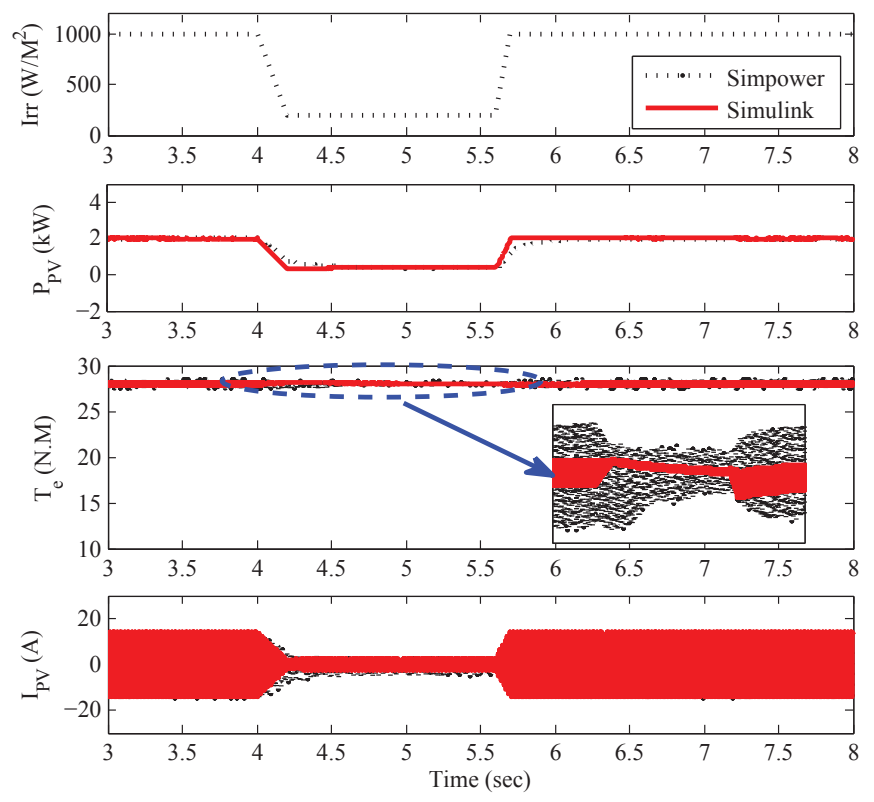

Fig. 9. Simulation results for the effect of irradiance change.

the PV power which follows the irradiance command. The PV power of the analytical model is set to follow the change of the irradiance. It is noticed that the maximum power level ( 2 $\mathrm{kW}$ ) is obtained when the irradiance is set to $1000 \mathrm{~W} / \mathrm{M}^{2}$. The third figure shows the electrical torque of the induction machine. When the irradiance is decreased due to clouds, the $\mathrm{PV}$ power is decreased, which leads to the decrease in the unbalance injection level to the system. The magnitude of the $120 \mathrm{~Hz}$ ripple has been decreased during the interval of 4 to 6 seconds. The last figure shows the PV current which has been decreased due to the irradiance change.

\section{Case Study 3}

In Case 3, impact of line length on system stability was investigated by both eigenvalue analysis and time-domain simulation in Matlab/SimPowerSystems. The eigenvalues of the system are presented in Table III. The movement of the dominant modes is presented in Fig. 10. One of the dominant modes is related to a real-axis eigenvalue. The grid line length has been changed from $3 \mathrm{~km}$ to $15 \mathrm{~km}$ in order to observe its effect on dynamics. It is worth mentioning that increasing the line length more than $15 \mathrm{~km}$ causes non-convergence of the sweeping method for initialization. Therefore the results are only shown for the initial conditions where the system is able to converge. It can be found from Fig. 10 that as the line length increases, the real-axis eigenvalue will move to the right half plane. This can cause voltage instability of the system. 
TABLE III

EIGENVALUE COMPARISON FOR DIFFERENT GRID LENGTH

\begin{tabular}{|c|c|c|c|c|c|c|c|c|c|}
\hline \multicolumn{3}{|c|}{$l=3 \mathrm{~km}$} & \multicolumn{3}{|c|}{$l=10 \mathrm{~km}$} & \multicolumn{3}{|c|}{$l=15 \mathrm{~km}$} & \multirow[t]{2}{*}{ dominant State } \\
\hline Eigenvalue & damping ratio $\%$ & frequency $(\mathrm{Hz})$ & Eigenvalue & damping ratio \% & frequency $(\mathrm{Hz})$ & Eigenvalue & damping ratio $\%$ & frequency $(\mathrm{Hz})$ & \\
\hline$-967 \pm 5848 \mathrm{i}\}$ & 16.31 & $\overline{931)}$ & $-984 \pm 3942 \mathrm{i}$ & 24.23 & 627 & $-993 \pm 3411 i$ & 27.95 & $\overline{543)}$ & \\
\hline$-993 \pm 5607 i\}$ & $17.43\}$ & $892\}$ & $-973 \pm 3700 \mathrm{i}\}$ & 25.42 & $589\}$ & $-968 \pm 3120 \mathrm{i}$ & $29.64\}$ & $497\}$ & $V_{G}, I$ \\
\hline$-133.37 \pm 308 i$ & 39.68 & 49 & $-123.21 \pm 321 i$ & 35.81 & 51 & $-116.74 \pm 328 \mathrm{i}$ & 33.53 & 52 & $I_{p s}$ \\
\hline$-137.96 \pm 117 \mathrm{i}$ & 76.23 & 18.6 & $-126.8 \pm 107 i$ & 76.49 & 17 & $-119.66 \pm 103 i$ & 75.9 & 16.3 & $I_{p r}$ \\
\hline$-133.37 \pm 445 \mathrm{i}$ & 28.68 & 70.9 & $-123.21 \pm 432 \mathrm{i}$ & 27.38 & 69 & $-116.74 \pm 426 \mathrm{i}$ & 26.43 & 67.8 & $I_{n s}$ \\
\hline$-137.96 \pm 637 \mathrm{i}$ & 21.17 & 101 & $-126.81 \pm 647 \mathrm{i}$ & 19.23 & 103 & $-119.67 \pm 651 \mathrm{i}$ & 18.07 & 104 & $I_{n r}$ \\
\hline$-0.75 \pm 75 \underline{4}$ & _ 0.1 & 120 & _ _ - $-0.6 \underline{6} \pm \_75 \underline{4}$ & 0.09 & $12 \underline{0}$ & $-0.60 \pm 75 \underline{4}$ & $0.0 \underline{8}$ & 120 & $\omega_{r 2}$ \\
\hline $1-1.52 \pm 0 \mathrm{i}$ & 100 & 0 & $-1.36 \pm 0 \mathrm{i}$ & 100 & 0 & $-1.21 \pm 0 \mathrm{i}$ & 100 & 0 & $\omega_{r}$ \\
\hline
\end{tabular}

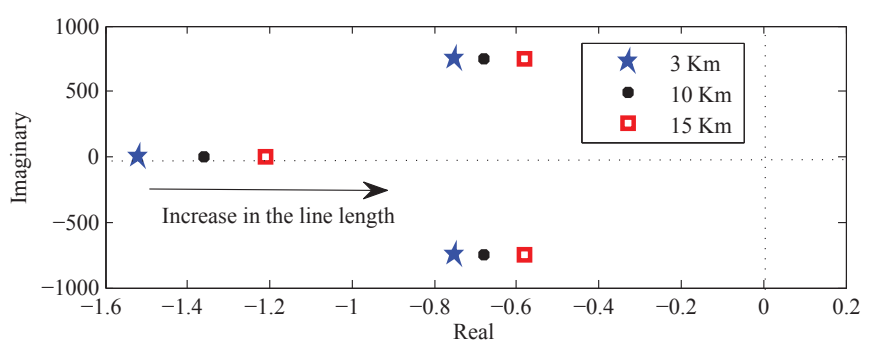

Fig. 10. The dominant modes $(120 \mathrm{~Hz}$, and the voltage stability mode) by increasing the line length.

In time-domain simulations, a dynamic event to increase the grid line from $3 \mathrm{~km}$ to $30 \mathrm{~km}$ was triggered. Initially the grid connection consists of two parallel lines. At $t=4 \mathrm{~s}$, a breaker of one line is opened so the effective line impedance increases suddenly. Such an event causes the voltage stability mode to move to the right half plane (RHP). The stator voltage of the induction machine decreases significantly as shown in Fig. 11.

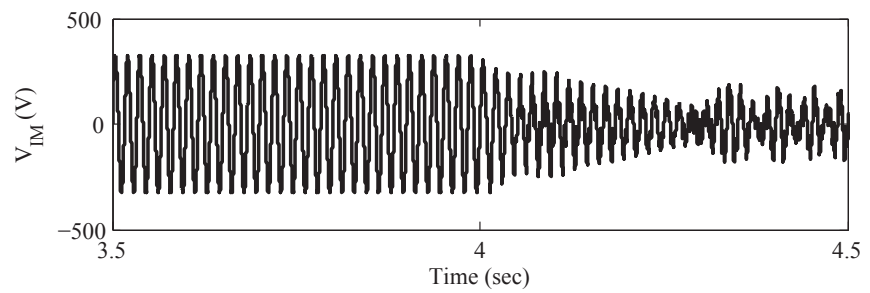

Fig. 11. Stator voltage when the grid line length increases from $3 \mathrm{kM}$ to 30 kM. Simulation results were produced by Matlab/SimPowerSystems.

Fig. 12 presents the dynamic response of the RMS value from 3.5 seconds to 6 seconds, which clearly shows the decline of the voltage magnitude.

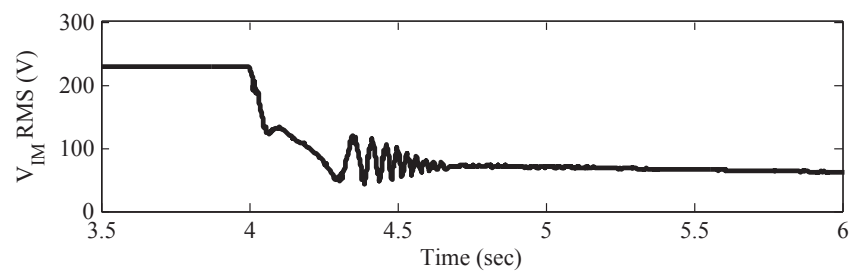

Fig. 12. RMS stator voltage when the grid line length increases from $3 \mathrm{kM}$ to $30 \mathrm{kM}$. Simulation results were produced by Matlab/SimPowerSystems.

Due to the decrease of the stator voltage and system voltage magnitude, for the induction machine, its electromagnetic torque will decrease and its rotor speed will decrease as shown in Fig. 13 (a) and (b). For the PV, since the reference power is kept intact, the reference current increases due to the decrease of the voltage. In turn, the PV current's magnitude increases as shown in Fig. 13. The entire system becomes unstable.
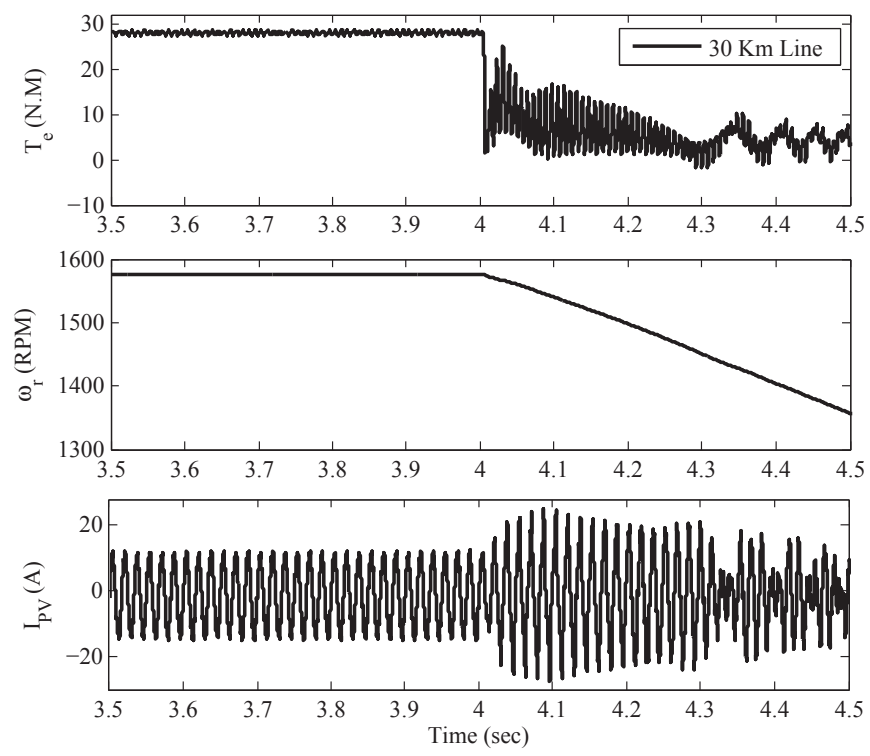

Fig. 13. Simpowersystems simulation results for the effect of grid line length increase. (a) torque; (b) rotating speed; (c) instantaneous current from PV.

\section{Remarks on simulation time}

In the previous sections, it has been demonstrated that timedomain simulation can be carried out by the Simulink model and the detailed model in SimPowerSystems. Due to its modeling details, the simulation time for the SimPowerSystems is long. A comparison (Table IV) has been carried out to show the simulation time difference between the two models. Table

TABLE IV

COMPARISON OF SIMULATION TIME BETWEEN TWO MODELS

\begin{tabular}{|c|c|c|}
\hline Time to be simulated & SimPowerSystems & Simulink \\
\hline $2 \mathrm{sec}$ & $4 \mathrm{~min}$ and $12 \mathrm{sec}$ & $2 \mathrm{sec}$ \\
$4 \mathrm{sec}$ & $9 \mathrm{~min}$ and $55 \mathrm{sec}$ & $4 \mathrm{sec}$ \\
$8 \mathrm{sec}$ & $18 \mathrm{~min}$ and $33 \mathrm{sec}$ & $6 \mathrm{sec}$ \\
$100 \mathrm{sec}$ & Memory error & $58 \mathrm{sec}$ \\
\hline
\end{tabular}

IV shows that the analytical model can be simulated in a much 
shorter period of time compared with the SimPowerSystems model.

\section{CONCLUSION}

In this paper, a dynamic phasor-based dynamic model was derived for an unbalanced distribution system consisting of a single-phase PV, a three-phase induction machine and a threephase power factor correction capacitor. The model is capable of fast time-domain simulation and small-signal analysis. The model's accuracy in capturing time-domain dynamics has been validated by Matlab/SimPowerSystems based simulation. The model's capability of small-signal analysis was also demonstrated. The eigenvalue analysis results corroborate with timedomain simulation results in Matlab/SimPowerSystems.

\section{APPENDIX}

TABLE V

PARAMETERS OF THE INDUCTION MACHINE

\begin{tabular}{|c|c|}
\hline Total capacity & $5.5 \mathrm{kVA}$ \\
\hline Nominal voltage & $400 \mathrm{~V}$ \\
\hline Frequency & $60 \mathrm{~Hz}$ \\
\hline$R_{s}$ & $2.52 \Omega$ \\
\hline$R_{r}$ & $2.67 \Omega$ \\
\hline$X_{l s}$ & $3.39 \Omega$ \\
\hline$X_{l r}$ & $3.39 \Omega$ \\
\hline$X_{M}$ & $197 \Omega$ \\
\hline$J$ & $0.486 \mathrm{~kg} . \mathrm{m}^{2}$ \\
\hline$P$ (poles) & 4 \\
\hline
\end{tabular}

TABLE VI

PARAMETERS OF PV

\begin{tabular}{|c|c|}
\hline Total capacity & $2000 \mathrm{~W}$ \\
\hline Frequency & $60 \mathrm{~Hz}$ \\
\hline$L_{a}$ & $0.01 \mathrm{H}$ \\
\hline$L_{b}$ & $0.02 \mathrm{H}$ \\
\hline$C a p$ & $3 \mu \mathrm{H}$ \\
\hline$K_{p}(P L L)$ & 180 \\
\hline$K_{i}(P L L)$ & 3200 \\
\hline$K_{p}(P R)$ & 200 \\
\hline$K_{i}(P R)$ & 1500 \\
\hline
\end{tabular}

TABLE VII

LINE DATA OF THE NETWORK

\begin{tabular}{|c|c|c|c|}
\hline Line No & Line Type & $\mathrm{Z}(\Omega / \mathrm{km})$ & Length $(\mathrm{m})$ \\
\hline 1 & $Z_{G r i d}$ & $0.579+\mathrm{j} 1.75$ & 105 \\
2 & $Z_{I M}$ & $0.497+\mathrm{j} 2.47$ & 105 \\
3 & $Z_{P V}$ & $0.462+\mathrm{j} 0.564$ & 30 \\
\hline
\end{tabular}

\section{REFERENCES}

[1] M. Braun, G. Arnold, and H. Laukamp, "Plugging into the zeitgeist," IEEE Power Energy Mag., vol. 7, no. 3, pp. 63-76, 2009.

[2] A. K. Abdelsalam, A. M. Massoud, S. Ahmed, and P. N. Enjeti, "High-performance adaptive perturb and observe MPPT technique for photovoltaic-based microgrids," IEEE Trans. Power Electron., vol. 26, no. 4, pp. 1010-1021, 2011.

[3] H. Kanchev, D. Lu, F. Colas, V. Lazarov, and B. Francois, "Energy management and operational planning of a microgrid with a PV-based active generator for smart grid applications," IEEE Trans. Ind. Electron., vol. 58, no. 10, pp. 4583-4592, 2011.
[4] K. Tan, P. So, Y. Chu, and M. Chen, "Coordinated control and energy management of distributed generation inverters in a microgrid," IEEE Trans. Power Del., vol. 28, no. 2, pp. 704-713, Apr. 2013.

[5] PSCAD Manual, Manitoba HVDC Research Center. [Online]. Available: www.pscad.com

[6] SimPowerSystems For Use with Simulink ${ }^{\circledR}$, Trans Énergie Technologies Hydro-Québec. [Online]. Available: http://www.mathworks.com

[7] J. Sun, "Small-signal methods for ac distributed power systems-a review," IEEE Trans. Power Electron., vol. 24, no. 11, pp. 2545-2554, 2009.

[8] A. M. Stankovic, B. C. Lesieutre, and T. Aydin, "Modeling and analysis of single-phase induction machines with dynamic phasors," IEEE Trans. Power Syst., vol. 14, no. 1, pp. 9-14, 1999.

[9] A. M. Stankovic, S. R. Sanders, and T. Aydin, "Dynamic phasors in modeling and analysis of unbalanced polyphase ac machines," IEEE Trans. Energy Convers., vol. 17, no. 1, pp. 107-113, 2002.

[10] A. M. Stankovic and T. Aydin, "Analysis of asymmetrical faults in power systems using dynamic phasors," IEEE Trans. Power Syst., vol. 15, no. 3, pp. 1062-1068, 2000.

[11] P. C. Stefanov and A. M. Stankovic, "Modeling of UPFC operation under unbalanced conditions with dynamic phasors," IEEE Trans. Power Syst., vol. 17, no. 2, pp. 395-403, 2002.

[12] P. Mattavelli, A. M. Stankovic, and G. C. Verghese, "SSR analysis with dynamic phasor model of thyristor-controlled series capacitor," IEEE Trans. Power Syst., vol. 14, no. 1, pp. 200-208, 1999.

[13] G. Díaz, C. Gonzalez-Moran, J. Gomez-Aleixandre, and A. Diez, "Complex-valued state matrices for simple representation of large autonomous microgrids supplied by $p q$ and $v f$ generation," IEEE Trans. Power Syst., vol. 24, no. 4, pp. 1720-1730, 2009.

[14] M. Daryabak, S. Filizadeh, J. Jatskevich, A. Davoudi, M. Saeedifard, V. Sood, J. Martinez, D. Aliprantis, J. Cano, and A. Mehrizi-Sani, "Modeling of LCC-HVDC systems using dynamic phasors," IEEE Trans. Power Del., vol. 29, no. 4, pp. 1989-1998, Aug 2014.

[15] V. A. Caliskan, O. Verghese, and A. M. Stankovic, "Multifrequency averaging of dc/dc converters," IEEE Trans. Power Electron., vol. 14, no. 1, pp. 124-133, 1999.

[16] R. Salim and R. Ramos, "A model-based approach for small-signal stability assessment of unbalanced power systems," IEEE Trans. Power Syst., vol. 27, no. 4, pp. 2006-2014, Nov. 2012.

[17] N. L. Soultanis, S. A. Papathanasiou, and N. D. Hatziargyriou, "A stability algorithm for the dynamic analysis of inverter dominated unbalanced lv microgrids," IEEE Trans. Power Syst., vol. 22, no. 1, pp. 294-304, 2007.

[18] J. Sun, "Impedance-based stability criterion for grid-connected inverters," IEEE Trans. Power Electron., vol. 26, no. 11, pp. 3075-3078, 2011.

[19] O. Gomis-Bellmunt, A. Junyent-Ferre, A. Sumper, and J. BergasJan, "Ride-through control of a doubly fed induction generator under unbalanced voltage sags," IEEE Trans. Energy Convers., vol. 23, no. 4, pp. 1036-1045, 2008.

[20] M. Ciobotaru, R. Teodorescu, and F. Blaabjerg, "Control of single-stage single-phase pv inverter," in European Conference on Power Electronics and Applications. IEEE, 2005, pp. 10-pp.

[21] C. Meza, J. J. Negroni, D. Biel, and F. Guinjoan, "Energy-balance modeling and discrete control for single-phase grid-connected pv central inverters," IEEE Trans. Ind. Electron., vol. 55, no. 7, pp. 2734-2743, 2008.

[22] Y. Yang, K. Zhou, and F. Blaabjerg, "Harmonics suppression for single-phase grid-connected photovoltaic systems in different operation modes," in The Applied Power Electronics Conference and Exposition, 2013.

[23] Y. Wang, P. Zhang, W. Li, W. Xiao, and A. Abdollahi, "Online overvoltage prevention control of photovoltaic generators in microgrids," IEEE Trans. Smart Grid, vol. 3, no. 4, pp. 2071-2078, Dec. 2012. 


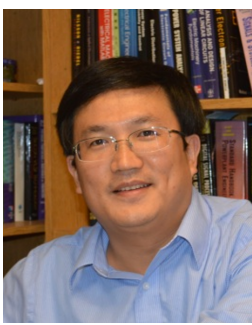

Zhixin Miao (S'00 M'03 SM'09) received the B.S.E.E. degree from the Huazhong University of Science and Technology, Wuhan, China, in 1992, the M.S.E.E. degree from the Graduate School, Nanjing Automation Research Institute, Nanjing, China, in 1997, and the Ph.D. degree in electrical engineering from West Virginia University, Morgantown, in 2002.

Currently, he is with the University of South Florida (USF), Tampa. Prior to joining USF in 2009, he was with the Transmission Asset Management Department with Midwest ISO, St. Paul, MN, from 2002 to 2009. His research interests include power system stability, microgrid, and renewable energy.

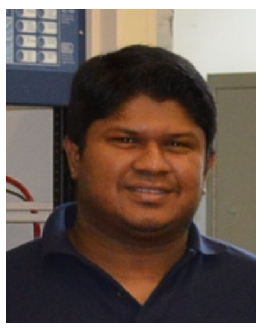

Lakshan Piyasinghe is a Ph.D. student at University of South Florida (USF). He received his Bachelor degree in Electrical Engineering in 2006 from University of Moratuwa, Sri Lanka. He started his Ph.D. study at USF in Fall 2010 and his research interests include dynamic modeling and analysis of power electronic systems and power systems.

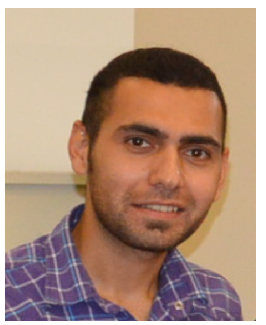

Javad Khazaei is a Ph.D student at University of South Florida (USF). He received his Bachelor degree in Electrical Engineering from Mazandaran University (2009) and Master degree from Urmia University (2011) in Iran. He started his Ph.D study at USF in Summer 2013 and his research interests include Smart Grid modeling, Renewable Energy Integration, and Power Electronics.

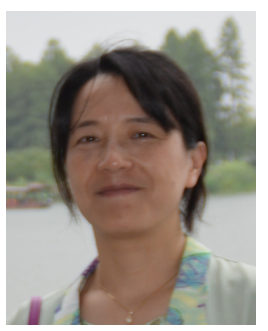

Lingling Fan (SM'08) received the B.S. and M.S. degrees in electrical engineering from Southeast University, Nanjing, China, in 1994 and 1997, respectively, and the Ph.D. degree in electrical engineering from West Virginia University, Morgantown, in 2001. Currently, she is an Associate Professor with the University of South Florida, Tampa, where she has been since 2009. She was a Senior Engineer in the Transmission Asset Management Department, Midwest ISO, St. Paul, MN, form 2001 to 2007, and an Assistant Professor with North Dakota State University, Fargo, from 2007 to 2009. Her research interests include power systems and power electronics. Dr. Fan serves as a technical program committee chair for IEEE Power System Dynamic Performance Committee and an editor for IEEE Trans. Sustainable Energy. 